\title{
246 PROMOTING HEALTH RELATED SPORT BY USING LIVING
} LAB

Paula M J Harmokivi-Saloranta, Satu Parjanen Lahti University of Applied Sciences, Hoitajankatu, Lahti, Finland

10.1136/bjsm.2010.078725.246

The purpose of this presentation is to introduce the Living Lab project. Increasing physical activity is one of the main objectives in the prevention and treatment of lifestyle-related diseases. The aim of this project is to develop new innovative services of physical activity for sedentary populations. The services of physical activity will be developed by using a Living Lab. Living Lab is a system for building a future in which real-life user-driven development and innovation will be a normal co-creation technique for new products, services and societal infrastructure. In the Living Lab development projects, the users take active part in development and innovation. The user not only supplies information to the developers but also is part of the development team, for example, generating ideas. In this project, there are 12 different user groups, for example, children, young people, adults, businessmen and unemployed. These user groups are trying to find answers to questions: 'Why doesn't citizen go in for physical activity and what it should do that he/she would be physically active?' Finding a solution to an everyday problem can improve the quality of life for a whole user group and at the same time act as the start of a new and successful business venture. For example, stories, essays and interviews will be used as methods. Materials will be analysed and different stories can be obtained on how to activate people to health-related sports. In addition, models will be developed that encourage people to participate in physical activities that promote health. 